\title{
Entrepreneurship Through Start-ups in Hill Areas Using Photovoltaic Systems
}

\author{
Chandani Sharma*, Anamika Jain \\ Department of Electronics and Communication Engg, Graphic Era University, Dehradun, India \\ ${ }^{*}$ Corresponding author, e-mail: Chandani19nov@gmail.com, Mob: 8958308881
}

\begin{abstract}
There is large potential for generating solar power in Uttarakhand (India) endowed with natural resources. The extensive use of solar energy through solar PV panels in Distributed and Renewable Electricity Generation is significant to utilize multi climatic zones of hilly areas. In this regard, UREDA (Uttarakhand Renewable Energy Development Agency) targets to achieve a huge boost of solar PV battery backup with approved subsidy budget of INR 6 billion to 50 billion by 2019/20 under JNNSM (Jawaharlal Nehru National Solar Mission). This investment will increase productivity, enhance employment opportunities and improve quality of education. However, maximization of power output from panels used for same is achieved through use of MPPT (Maximum Power Point Trackers). The commercially installed solar power systems can be made to accomplish higher efficiency by implementing MPPT systems in start ups. In this paper, the effort is made to use MPPT system designed by intelligent controller for implementation in PV based utility systems. The regulated voltage output from MPPT system is obtained irrespective of fluctuations in environment. These variations are tested for changing temperature and irradiance due to shading or partial unavailability of sun. The results of same have been optimized through MATLAB/SIMULINK. The model designed is intended to be a beneficial source for PV engineers and researchers to provide high efficiency with the use of MPPT.
\end{abstract}

Keywords: distributed and renewable electricity generation, UREDA, JNNSM, MPPT, MATLAB/SIMULINK

\section{Introduction}

Energy is the linchpin of our economy and a vital component for all progress on earth. As per energy statistics of TIFAD (Technical Information Forecasting Assessment Databank) proper energy balance is required to be established to save energy crisis. Currently, the consumption of Non Renewable sources like coal, natural gas, oil and nuclear are used to meet energy demands. Global Survey states that total non renewable energy sources used for electricity generation are 10.8 million [1]. Also if the consumption of fossil fuels continues at same rate, all sources will gradually deplete by end of this century.

Reviews show that one third of world's population does not have access to electricity and not connected to national grid. India faces acute energy scarcity hampering growth and progress to a large extent. As such searching another alternative is necessary to meet rapid growing needs of energy. Solar radiation received on earth is a direct source for generating heat, electricity and power to meet demands of energy efficient systems throughout the world. Solar electric energy demand has grown consistently by 20 to $25 \%$ per annum over past 20 years due to decreasing cost and prices. The decline has driven (a) increasing efficiency of solar cells (b) manufacturing techniques and (c) economies of scale. Thus, Solar energy amongst various RET (Renewable Energy Technology) being abundant, clean and green is an evergreen solution to advance electricity production globally [2].

Solar energy is available for 300 days with average irradiance in range of $4-7 \mathrm{KW} / \mathrm{m}^{2}$ annually. The abundance of solar energy appears as an ultimate choice for power consumption and distribution applications. In India, specifically state of Uttarakhand receives 4.5 to 5.5 $\mathrm{KW} / \mathrm{m}^{2}$ irradiance throughout the year around [3]. The state of Uttarakhand also provides climatic benefits of three types (a) cold and sunny/cold and cloudy for hilly upper shivaliks, (b) semi moderate as in Dehradun and (c) plain composite type as in Haridwar, Roorkee, Kashipur and Rudrapur. Power demand in state during recent years has grown from $10 \%$ to $15 \%$ annually. Moreover, hydropower is beaten in Uttarakhand as compared to solar energy that can 
be considerably used for roof top and wastelands. Solar systems are of two types grid connected and stand alone. When large number of solar panels are used for installation grid connection is established serving as a power plant for region while small scale electrical loads designed to meet direct distribution in home is done through stand alone devices supported with battery back-ups [4].

Photovoltaic (PV) systems refer to the systems converting solar energy into electricity. PV system directly converts sunlight into electricity either through direct capture or distributed reception. Distributed reception refers to change in panel output due to deviations in temperature and irradiance by partial or complete shaded environmental conditions. In Uttarakhand, Solar power plants are already available in range of $300 \mathrm{~W}$ to $100 \mathrm{KW}$ extended upto 500KW with battery back-up upto 44MW through PV designing scheme run by UREDA [5]. In this context, Pan-India exposure plan integrates four distinct approaches through (a) grid connected power plants (b) roof top solar plants (c) solar pumping sets and (d) solar street lights.

The use of PV plants for electricity production helped masses to retain their homes in Chaumasi village where 35 families used to abandon amongst 68 families on account of non availability of electricity. After great disaster, Kalimath valley again revolutionized through use of PV devices in home electricity distribution. The problems of transport due to heavy rains result frequent power cuts by disconnecting power supply as happened in Kotma village. The problem is solved by use of solar PV panel driven street lights and terrace lighting. Under JNNSM and MNRE (Ministry of New and Renewable Energy) joint ventures "off-grid and decentralized solar applications" for first phase of JNNSM, 33KV/11KV in 3-phase system and 440V/220V in 1phase system is achieved and in progress to set up 2000 units producing $44 \mathrm{MW}$ of electricity in second phase upto 2020 [6]. Amongst upcoming ventures, "Marvela" first solar city in Uttarakhand is being planned in Haridwar city. Garbage dump areas and broken roads when covered with panels promote infrastructure development. The unutilized hill tops/building rooftops and wastelands around buildings are being made to replace diesel generator sets used in load shedding by operating solar panel MPPT systems [7].

In the present paper, MPPT is developed for STC (Standard Test Conditions) as well as distributed environment conditions for varying temperature and irradiance. STC (Standard Test Condition) tend to maintain fixed $25^{\circ} \mathrm{C}$ temperature and irradiance $1 \mathrm{KW} / \mathrm{m}^{2}$ over panel surface. These conditions operate panel at MPP (Maximum power point). MPP describes a unique intersection point on panel that delivers maximum power output and efficiency from panel at STC. MPPT system maintains MPP. Using MPPT, the distributed energy across panel due to varying environment is efficiently captured and utilized [8]. The MPPT system developed in work is validated with commercially available Solarex MSX-60W panel [9]. The designed model meets all specifications of Solarex panel. Firstly system is simulated under STC and thereafter designed such that it maintains STC under fluctuating environment also to deliver MPP continuously. MPPT is designed using Buck (step down) converter and Fuzzy Logic Intelligent controller. The developed MPPT system regulates output voltage from panel and maximizes it relative to variations under distributed environmental conditions [10-14].

\section{Design of MPPT}

The commercial PV arrays that delivers $60 \mathrm{~W}$ at output by generating $21 \mathrm{~V}$ is Solarex MSX-60W. The panel is designed using Simulink modeling of solar cell equations through MATLAB. The equations modeled are:

(i) Thermal Voltage equation

$$
V_{T}=\frac{k_{B} T_{O P T}}{q}
$$

(ii) Diode Current equation

$$
I_{D}=N_{P} I_{S}\left(e \frac{\left(\frac{V}{N_{S}}+\frac{I R_{S}}{N_{S}}\right)}{N V_{T} C}-1\right)
$$

Bulletin of EEI Vol. 6, No. 2, June 2017 : $105-121$ 
(iii) Load Current equation

$$
I_{L}=I_{P h} N_{P}-I_{D}-I_{S H}
$$

(iv) Photo-current equation

$$
I_{P h}=\left[k_{i}\left(T_{O P T}-T_{R E F}\right)+I_{S C}\right] I_{R S}
$$

(v) Shunt Current equation

$$
I_{S H}=\frac{\left(I R_{S}+V\right)}{R_{S H}}
$$

(vi) Reverse Saturation Current equation

$$
I_{S}=\left(\frac{\left(I R_{S}\left(\frac{T_{O P T}}{T_{R E F}}\right)^{3} * q^{2} \frac{E_{g}}{N k_{B}} * e^{\left(\frac{1}{T_{O P T}}-\frac{1}{T_{R E F}}\right)}\right)}{R_{S H}}\right)
$$

(vii) Reverse Current equation

$$
I_{R S}=\left(\frac{I_{S C}}{e^{\left(\frac{q V O C}{k_{i} C T O P T}-\frac{1}{T_{R E F}}\right)}}\right)
$$

(viii) Output Power equation

$$
P=V I
$$

When above equations are rearranged to develop PV panel, the subsystem obtained appears as shown in Figure 1.

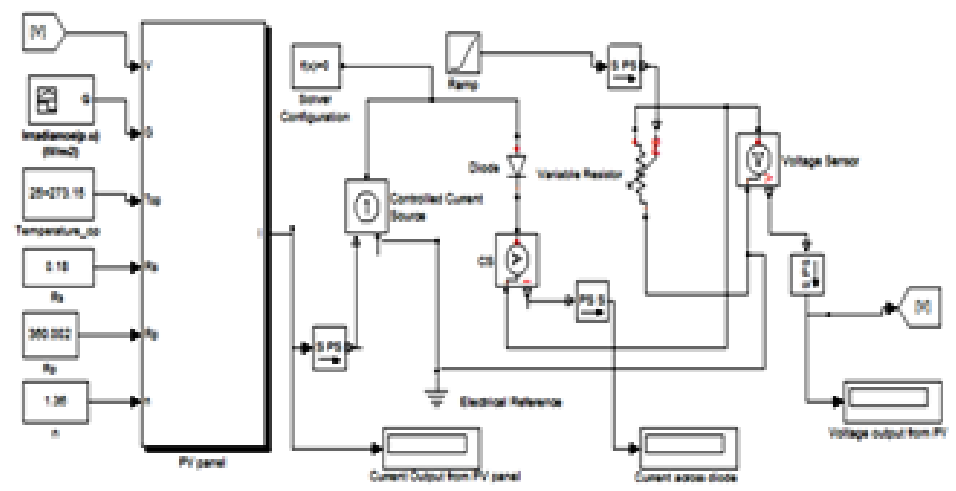

Figure 1. Solar panel subsystem

The modeled system is simulated for STC and specifications similar to Solarex MSX60W panel are obtained. The specifications obtained from designed panel are listed in Table 1.

Table 1. Specifications for Solarex and Model Developed

\begin{tabular}{ccc}
\hline \multirow{2}{*}{ Specification } & \multicolumn{2}{c}{$\mathrm{G}=1 \mathrm{KW} / \mathrm{m}^{2}$ and $\mathrm{T}=25^{\circ} \mathrm{C}$} \\
\cline { 2 - 3 } & Solarex MS-60W & Our Model \\
\hline $\mathrm{P}_{\mathrm{MPP}}$ & $60 \mathrm{~W}$ & $59.39 \mathrm{~W}$ \\
$\mathrm{~V}_{\mathrm{MP}}$ & $17.1 \mathrm{~V}$ & $16.64 \mathrm{~V}$ \\
$\mathrm{I}_{\mathrm{MP}}$ & $3.5 \mathrm{~A}$ & $3.567 \mathrm{~A}$ \\
$\mathrm{I}_{\mathrm{SC}}$ & $3.8 \mathrm{~A}$ & $3.7981 \mathrm{~A}$ \\
$\mathrm{~V}_{\mathrm{OC}}$ & $21.1 \mathrm{~V}$ & $21.07 \mathrm{~V}$ \\
\hline
\end{tabular}


The designed model on simulation at STC displays the I-V (Current Voltage) and P-V (Power Voltage) characteristic curves shown in Figure 2.

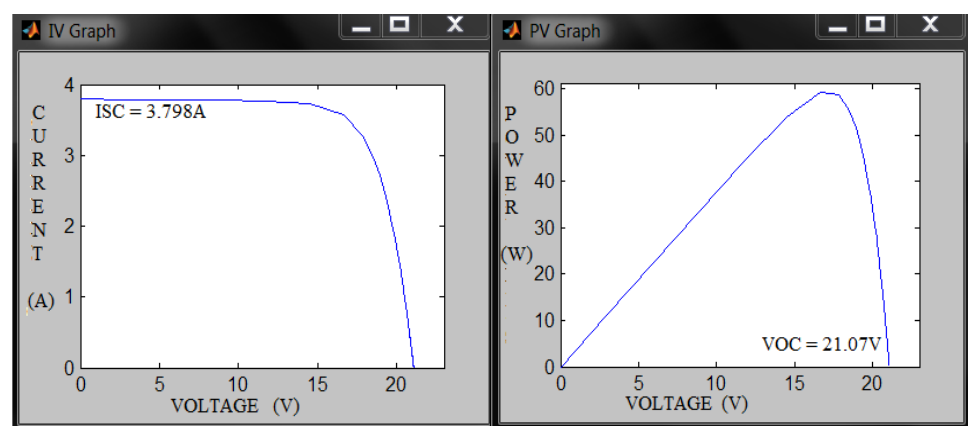

Figure 2. I-V and P-V characteristics of panel

It is clear from solar cell characteristics that they appear inverse exponential. The I-V characteristic curve represent panel output as perfect current source for maximum current i.e. short circuit current $\mathrm{I}_{\mathrm{SC}}$ and $\mathrm{P}-\mathrm{V}$ characteristic curve represent panel output as perfect voltage source for maximum voltage i.e. open circuit voltage $V_{\text {oc }}$. Since characteristic curves appear nonlinear, solar cell neither serves as a perfect current source nor perfect voltage source.

The two characteristic curves I-V and P-V intersect at point generated by short circuit current $I_{S C}$ taken $3.798 \mathrm{~A}$ and open circuit voltage $V_{O C}$ taken as $21.07 \mathrm{~V}$. This unique point is represented as Maximum power point and is shown in Figure 3.

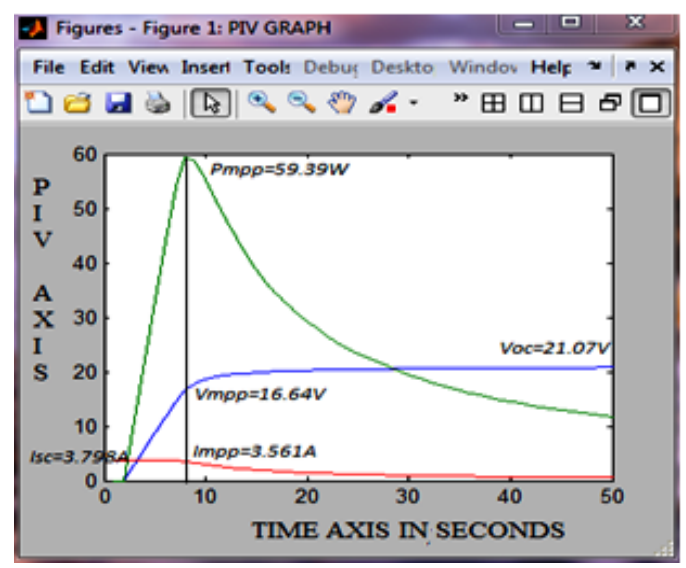

Figure 3. Determination of panel specifications

To obtain MPP under fluctuating environment conditions, it is necessary to combine PV system with converter and controller. The converter transforms value of output DC or AC as per requirement and controller maintains it throughout the system operation. The block diagram of assembled structure is referred as MPPT given in Figure 4. 


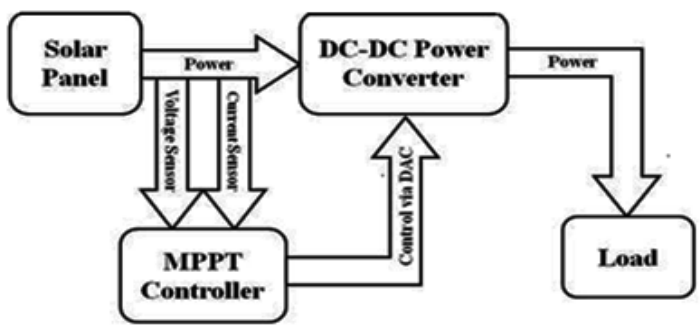

Figure 4. Block diagram of MPP tracker circuit

Since direct connection of panel with load is costly and losses generating therefore converter is used as an interface for panel output (DC in present work). Review shows that Buck (step down) Converters provide advantages of simpler design, easier implementation, current limiting and short circuit protection over other converters. Thus, DCM (Direct Component Model) of Buck converter is modeled to obtain converted dc output as shown in Figure 5.

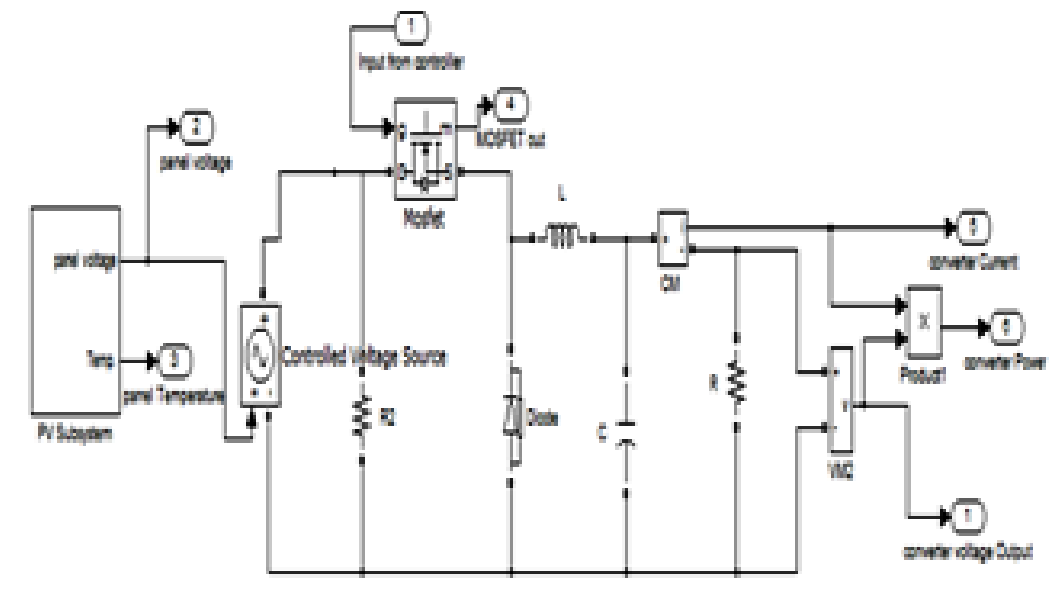

Figure 5. Buck converter using direct components

The output voltage of converter is driven by switch (MOSFET: Metal Oxide Semiconductor Field Effect Transistor) which conducts and develops output across load resistor. The converter is combined with PV subsystem and is tested for varying values of temperature and irradiance. The readings after simulation for distributed conditions i.e. variable temperature and irradiance are given in Table 2. The converter output voltage appears as displayed in Figure 6.

Table 2 Simulation of PV and converter subsystem

\begin{tabular}{ccc}
\hline $\mathrm{T}^{\circ} \mathrm{C}$ & $\mathrm{V}_{\text {OC }}$ desired $(\mathrm{V})$ & Converter Output $(\mathrm{V})$ \\
\hline 5 & 21.31 & 20.58 \\
10 & 21.25 & 20.88 \\
15 & 21.19 & 21.02 \\
20 & 21.13 & 21.03 \\
$\mathbf{2 5}$ & $\mathbf{2 1 . 0 7}$ & $\mathbf{2 1 . 0 1}$ \\
30 & 21.01 & 20.93 \\
35 & 20.95 & 20.79 \\
40 & 20.89 & 20.48 \\
45 & 20.83 & 20.06 \\
\hline
\end{tabular}




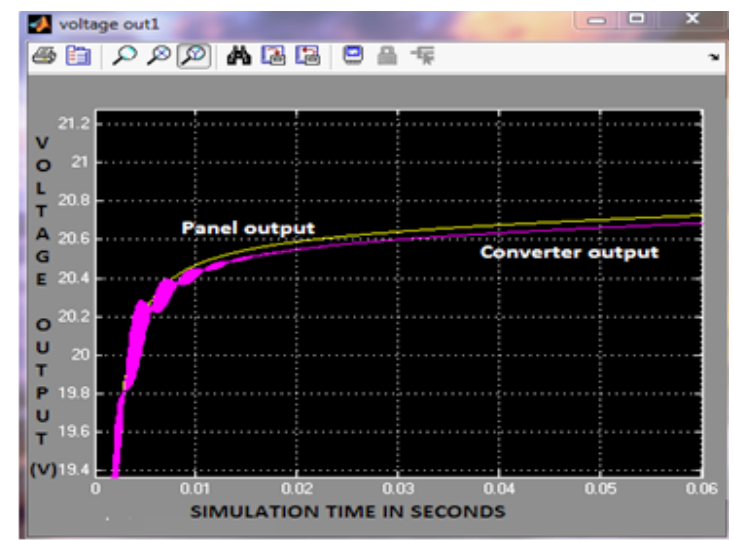

Figure 6. PV and converter subsystem voltage output

It is clear from PV and converter subsystem operation that there is large difference between desired $(21.07 \mathrm{~V})$ and obtained converter output $(21.01 \mathrm{~V})$. Thus system is not sufficient to deliver maximum output and needs to be connected with Controller for same. The effectiveness of converter operation is dependent on controller. A Controller generates control function for monitoring converter to get desired output from panel. For Buck converter, input is guided using Controller to deliver output voltage at capacitor and finally across load resistor.

There are different types of controllers available. The traditional approach used in designing conventional controllers was dependent on deterministic variables of yes-or-no type. The system responded to operator's experience by tuning the data collected by simulating PV model. The decision of the operator was not exact but considered good enough for normal functioning in the conditioning of process.

However, intelligent controllers particularly FLC (Fuzzy Logic controllers) offer a promising solution to this conceptual design through fuzzy modeling. This is an artificial intelligent system that removes the dependence on tuning system. FLC uses set of rules to automatically monitor system closer to MPP taken as set point. The diagram for FLC is shown in Figure 7.

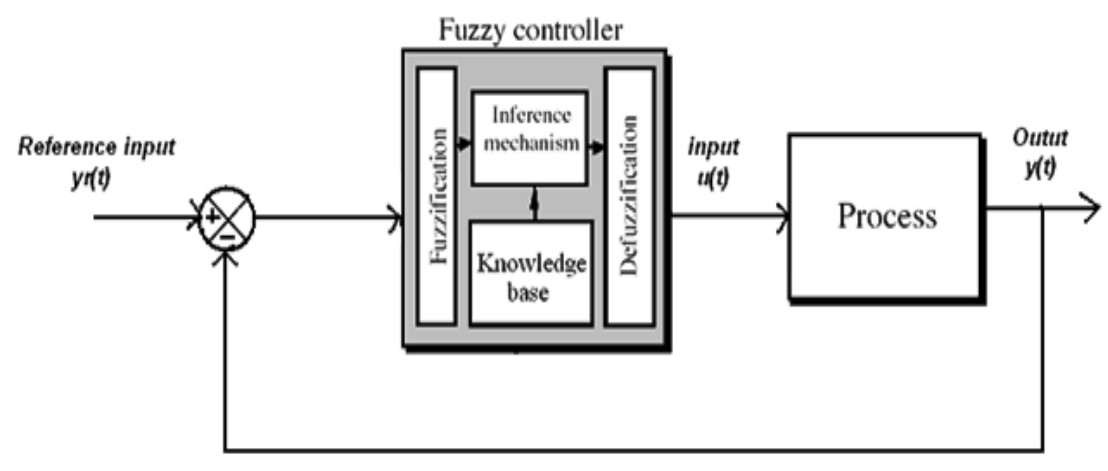

Figure 7. Fuzzy logic control loop system

The fuzzy logic is a non linear adaptive mechanism that using capability of transforming linguistic information and expert knowledge into control signals and therefore, are preferred over traditional approaches such as optimal and adaptive control techniques. Fuzzy logic control is most suitable for complex, ill defined and non linear problems as in case of PV systems.

A Mamdani type of Fuzzy Logic Controller is developed for controlling the MPP under changing environmental conditions. The input variables in a fuzzy control system are mapped by sets of membership functions known as "fuzzy sets". The process of converting a crisp input

Bulletin of EEI Vol. 6, No. 2, June 2017: 105-121 
value to a fuzzy value is called "fuzzification". Given "mappings" of input variables into membership functions and truth values, the controller then makes decisions for what action is to be taken based on a set of "rules". The universe of discourse (complete range) for both the input variables is chosen and the range of the input variables can be changed according to the changing demand for the varying input. Similarly, the universe of discourse (range) for the output variables is chosen for the varying input and MPP is monitored by the converter switching.

The fuzzy logic controller designed has two inputs and one output over sampling instant ' $n$ '. The error in voltage $E(n)$ equation 2.9/2.10 and change in error in voltage $\Delta E(n)$ equation 2.11 are taken as the inputs of the controller and controller duty cycle DC equation 2.12 is taken as the output/final control element of the controller. The Mamdani system designed is shown in Figure 8.

$E(n)=$ Set point value-Measured value

$$
\begin{aligned}
& E(n)=\frac{P(n)-P(n-1)}{I(n)-I(n-1)} \\
& \Delta \mathrm{E}(\mathrm{n})=\mathrm{E}(\mathrm{n})-\mathrm{E}(\mathrm{n}-1) \\
& D C=\frac{V_{\text {out }}}{V_{\text {in }}}
\end{aligned}
$$

where: $E(n) \quad=$ Error Input

$P(n) \quad=P V$ power computed at an instant $n$

$P(n-1)=P V$ power computed at an instant $n-1$

I (n) =PV current computed at an instant $\mathrm{n}$

I (n) =PV current computed at an instant $n-1$

$\Delta \mathrm{E}(\mathrm{n})=$ Change in Error Input

$E(n-1)=$ Error computed at an instant $n-1$

DC =Duty Cycle

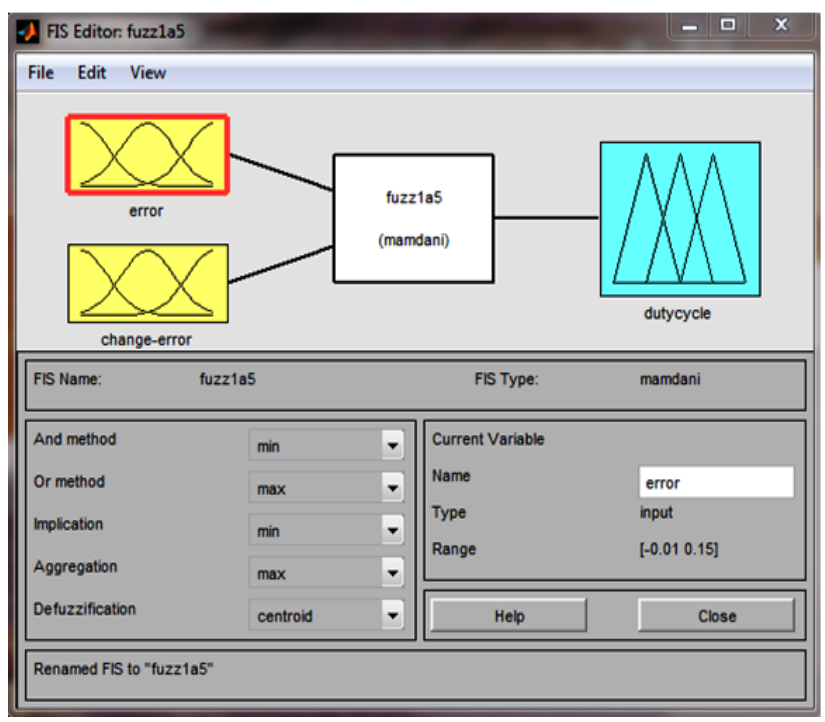

Figure 8. Matlab window showing the fuzzy logic controller for MPPT

Three membership functions are taken with crossover points less than 0.5 for inputs: error and change in error while taken greater than 0.5 for output duty cycle. The Matlab windows of Figure 9, 10, and 11 show the two inputs: $E(n), \Delta E(n)$ and an output DC for developed FLC. 


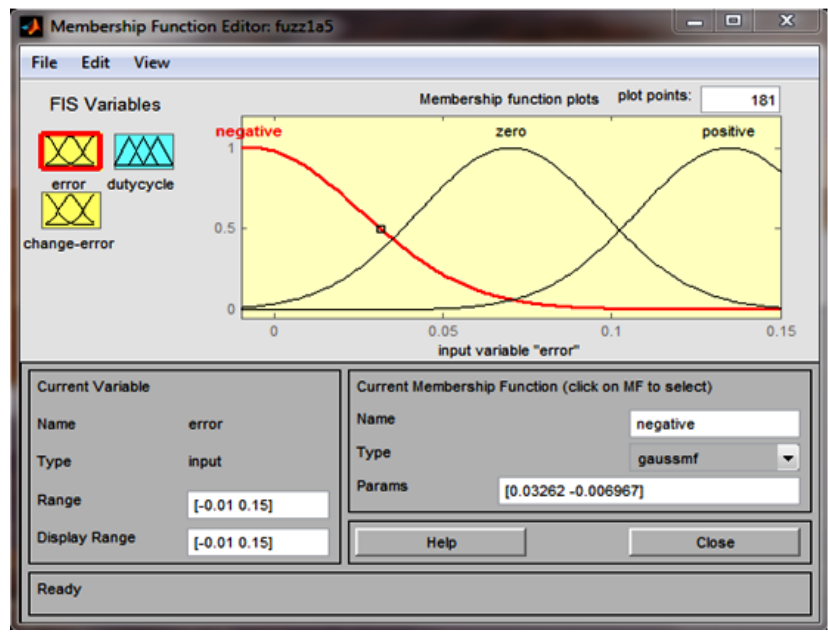

Figure 9. Matlab window showing the subsets of input $E$ (n) (error in voltage)

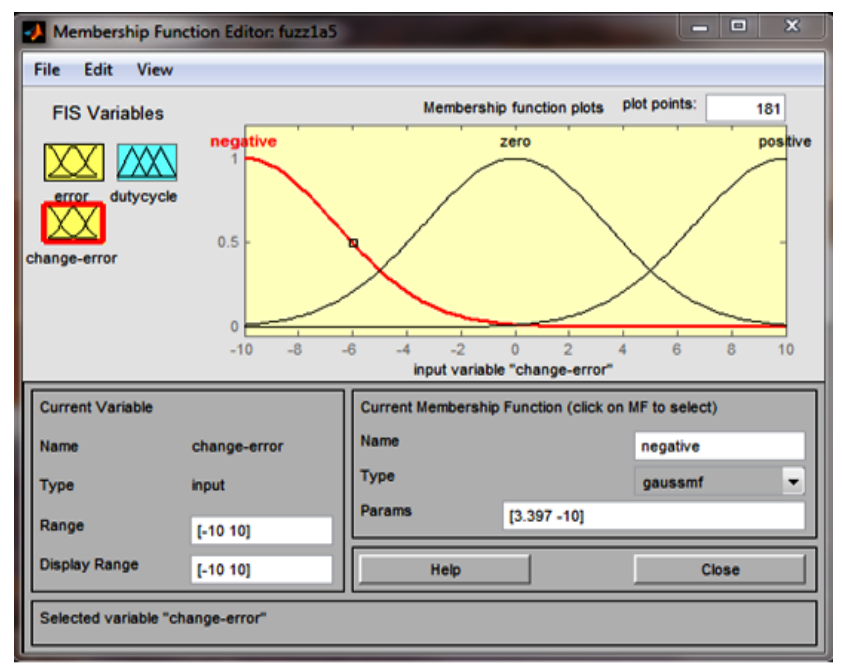

Figure 10. Matlab window showing the subsets of input $\Delta E(n)$ che (change in error in voltage)

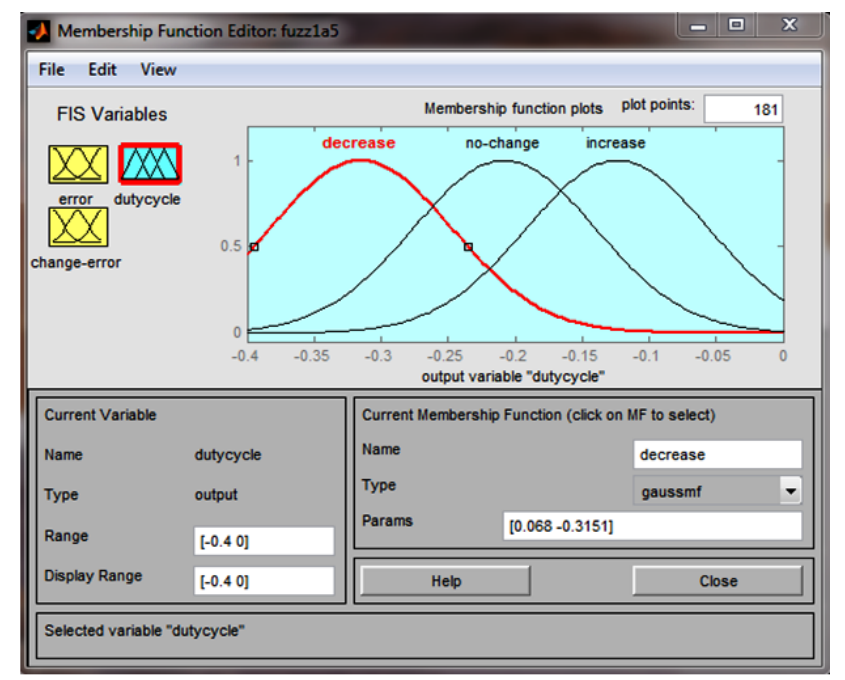

Figure 11. Matlab window showing the output duty cycle $D$ 
The fuzzy membership functions can be derived into a $3 \times 3$-rule matrix that consists of 9 rules. The rule matrix consists divided in two forms, Antecedents displayed alongside error and change in error followed by Consequents inside the table. Antecedents precede consequents. Figure 12 shows the fuzzy logic rules formulated for the designed FLC.

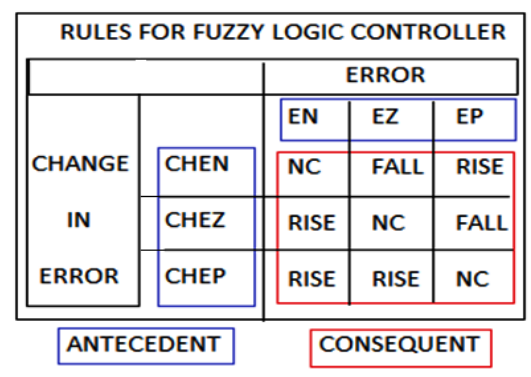

Figure 12. Fuzzy logic rule matrix

The fuzzy logic rule-base developed using subsets of inputs [error $E(n)$ and change in error $\Delta E(n)]$ and output [D] by functions [N negative, $Z$ zero, $P$ positive] are explained in rules as,

Rule 1: IF E (n) is N

Rule 2: IF E (n) is N

AND $\quad \triangle E(n) N$, THEN $D$ is not changed.

Rule 3: IF E (n) is N

AND $\quad \triangle E(n) Z$, THEN $D$ is decreased (fall).

Rule 4: IF E (n) is Z

Rule 5: IF E (n) is Z

AND $\quad \triangle E(n) P$, THEN $D$ is decreased (fall).

Rule 6: IF E (n) is Z

AND $\quad \triangle E(n) N$, THEN D is increased (rise).

AND $\quad \triangle E(n) Z$, THEN $D$ is not changed.

AND $\quad \triangle E(n) P$, THEN $D$ is decreased (fall)

Rule 7: IF E (n) is $P$ AND $\quad \triangle E(n) N$, THEN D is increased (rise).

Rule 8: IF $E(n)$ is $P \quad$ AND $\quad \triangle E(n) Z$, THEN D is increased (rise).

Rule 9: IF E (n) is $P \quad$ AND $\quad \triangle E(n) P$, THEN $D$ is not changed.

These nine rules are written in rule editor of the FIS and are fired when the input is given to the controller. Based on these rules, the system works, and the implication method is applied. The generalization or outputs obtained after the implication method are aggregated and the defuzzification is done to find the crisp output.

Defuzzification method is applied to obtain a quantitative summary and generate crisp output. The Defuzzification method used is the centroid method. The centroid of Gaussian membership functions termed as fuzzy centroid is calculated. The coordinate of the centroid is the defuzzified value and is given by equation (2.13).

$$
D=\frac{\sum_{j=1}^{n} \mu(\mathrm{Dj})-\mathrm{Dj}}{\sum_{j=1}^{n} \mu(\mathrm{Dj})}
$$

where: $\mathrm{D} \quad$ =Defuzzified value

$\mu(D j) \quad=$ Degree of membership function

Union of the membership functions is found by the MAX aggregation method. The 3D graph is represented in Figure 13, where $x$-axis is marked with the input e (error in voltage) and the $y$-axis is marked with the input che (change in error in voltage), while the z-axis is labeled as the output dc (duty cycle). 


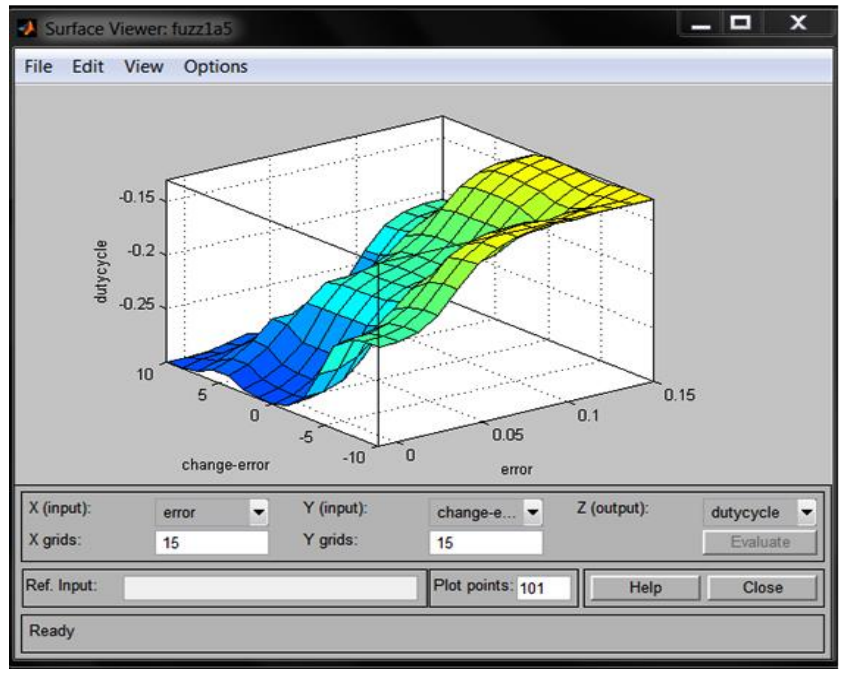

Figure 13. Matlab window showing 3D surface viewer

The Fuzzy Logic Controller so developed is incorporated with PV and converter system. The Simulink model of designed and developed MPPT using FLC is given in Figure 14.

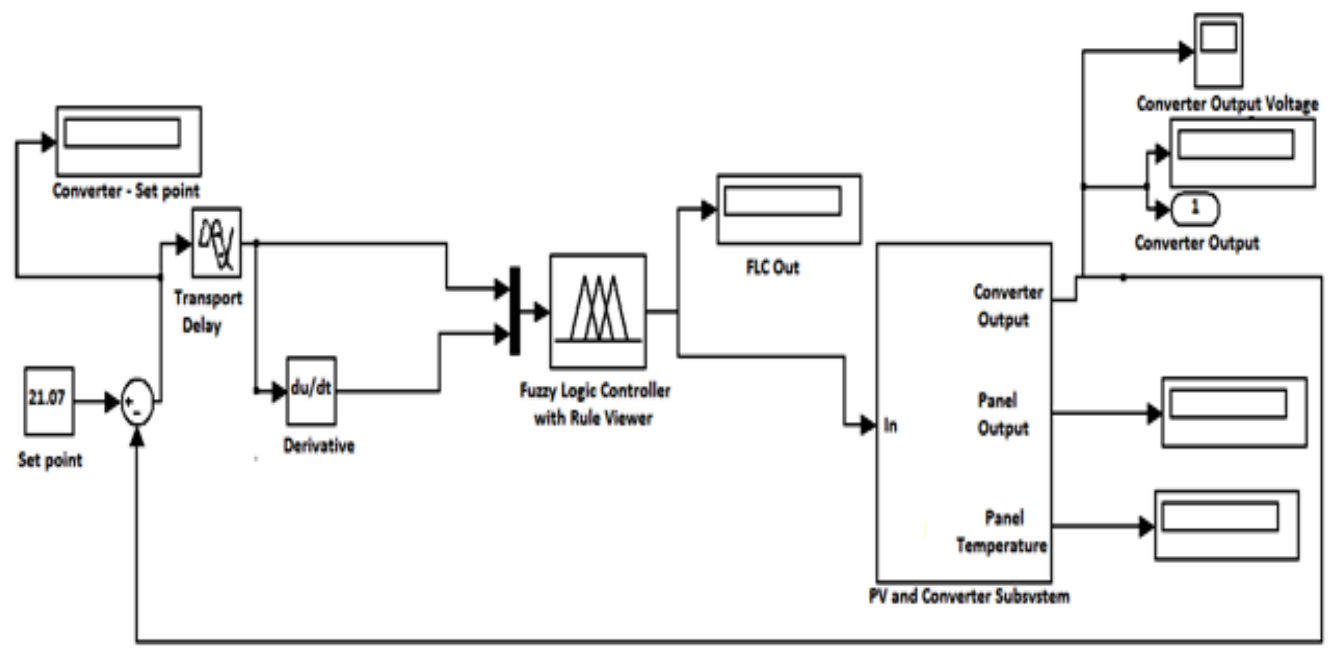

Figure 14. MPPT system using fuzzy logic controller

The results obtained after simulating above system for distributed conditions are tabulated in Table 3.

Table 3. FLC Simulation for PV and Converter Subsystem Using FLC

\begin{tabular}{cc}
\hline $\mathrm{T}^{\circ} \mathrm{C}$ & Converter output with FLC \\
\hline 5 & 20.84 \\
10 & 20.86 \\
15 & 20.89 \\
20 & 20.97 \\
$\mathbf{2 5}$ & $\mathbf{2 1 . 0 4}$ \\
30 & 21.05 \\
35 & 21.07 \\
40 & 21.08 \\
45 & 21.09 \\
\hline
\end{tabular}


It can be seen from Table that when results are improved using FLC in converter output $(21.04 \mathrm{~V})$ as compared to without controller $(21.01 \mathrm{~V})$. Figure 15 shows that appreciably good results are obtained for MPP controlled through FLC.

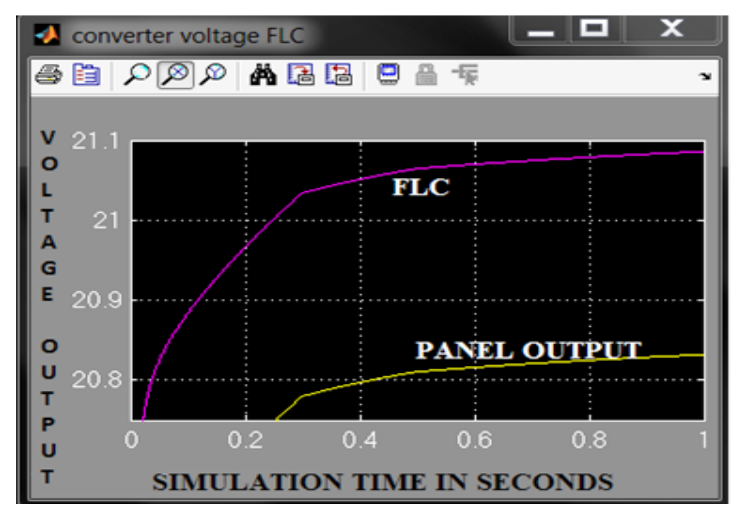

Figure 15. Converter output using FLC compared with panel output

Thus, model improves performance with MPPT using FLC. This system when incorporated in industries can serve as a boon for various utility based applications.

\section{Implementation of Designed MPPT System for Applications}

The developed MPPT system finds utility to serve in Uttarakhand's first solar city "Marvella" planned in Haridwar. The developed MPPT system when used in project may reduce cost and resources consumption with various applications [15-28]. These are illustrated under following sectors:

a. Grid and Roof-top electricity distribution (GRD)

The Mini PV Grid i.e. small power generation plant producing electricity upto $10 \mathrm{KW}$ can be used to light up five solar homes consuming full electricity throughout the day. The plant can be prepared by combining 170 Solarex MSX-60W panels. When connected with MPPT, the plant can generate electricity as per requirements within a solar home. The panels can be mounted at the sides of home or roof-top or along windows and sheds. As long as sunlight is available solar panels keep charging and storing energy in battery bank. The MPPT implementation can deliver respective output under shaded or partial cloudy days. At night, energy is retrieved back from charged batteries. Figure 16 shows how a solar powered home with rooftop structure dependent on electrification from panels will look like.

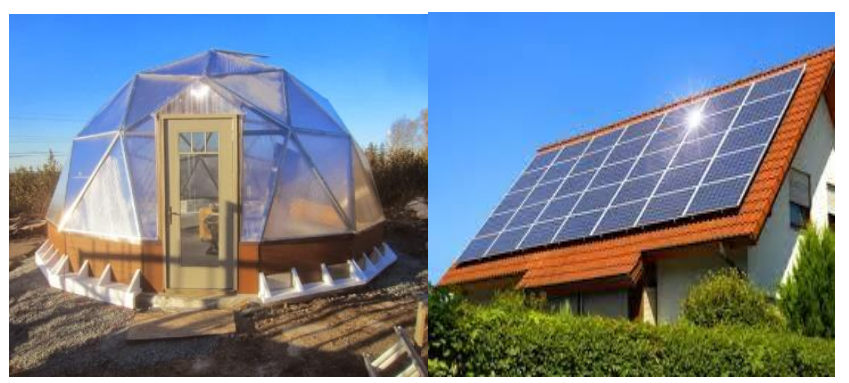

Figure 16. Solar powered home

b. Information and Communication Technology (ICT)

The designed MPPT system can serve in telecom towers required for communication within the city. As such 450 million liters of diesel can be saved annually required by a telecom 
tower to operate upon. Furthermore, Space requirement, emissions released, Opex (operational expenditure), Capex (Capital Expenditure), battery cost, fuel efficiency and loading usage within a day is less for Solar as compared to other tools. Figure 17 shows "solarised telecom tower technology" that can be integrated with system developed.

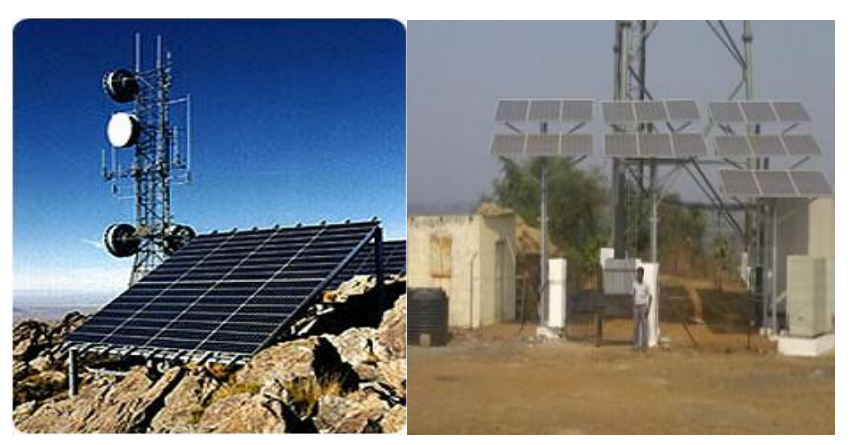

Figure 17. Solar operating mobile tower

c. Roadside lighting Devices (RLD)

RLD relates to equipments running by PV that can be worked for running smoothly on road and parking places. These can be used in solo purposes i.e. stand alone mini emergency lights, automatic street lights, parking sox lamps and solar projectors. They appear to be power saving in nature as direct supply light intensity consumes higher wattage as compared to green appliances. The MPPT system in present work delivers $21 \mathrm{~V}$ which is capable for all appliances operated upto $20 \mathrm{~V}$ as detailed above.

The most common green appliances are solar lanterns, street lights, CFL's, Sox lamps and power kits. These are shown in Figure 18. These devices possess characteristics like no vibration, fast startup, longer life, easy replacement and controls for lighting without requirement of starter or ballast. The main advantage of sox lamps are that their operating temperature easily fixates that can be provided by controls with no filaments to burn out.
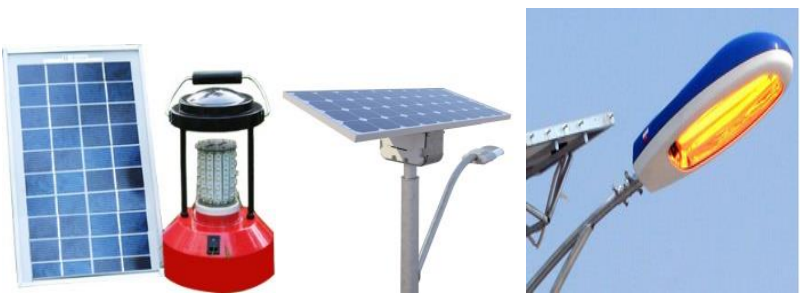

Figure 18. Solar lantern/street light/sox lamp

Other than sox lamps are solar projectors which are more advanced application of solar used for lighting complete village along with granary. Different sets of LED's, RGB lighting that can be effective in street lighting along with terrain lighting and traffic lighting too. These projectors are constructed using multicolored LED's as in Figure 19. They can prove as best alternative in shopping centers, hotels, entertainment, billboards, advertising barriers etc. 


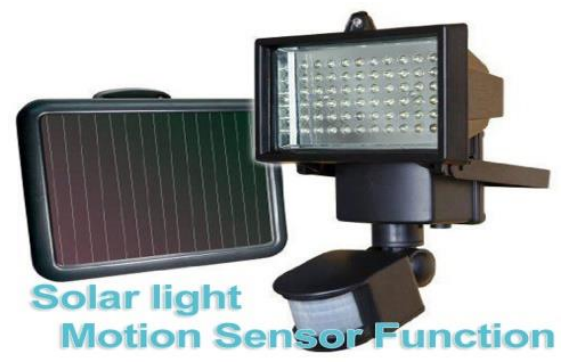

Figure 19. Solar projectors motion sensor function

Solar city road ways lighting can be powered without interruptions using these instruments. Theses significantly help in reducing load on direct electric supply.

d. Powered Electric Appliances (PEA)

PEA relates to equipments running by $P V$ that can be worked for running electric appliances. PEA operates through solar batteries, chargers, inverters and multitask operating devices for charging mobile phones, laptops, e-readers, tubes and electronic items. Solar chargers may overcharge and limit current if overcharged. During such condition, Solar Charge regulators or controllers can limit fixed output when employed using MPPT system. The same is shown in Figure 20. Another hi-tech application of charging and traveling is in Figure 21 showing solar soft rockers that are movable cabinets with chargers.

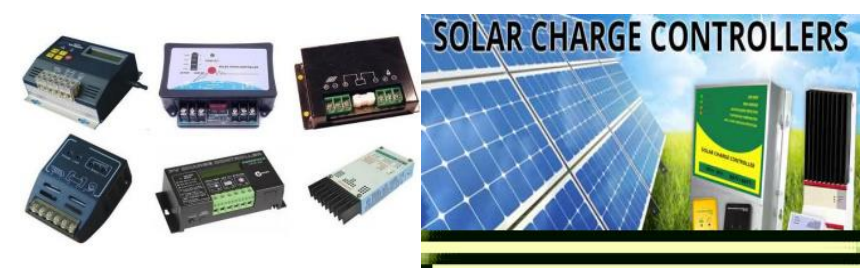

Figure 20. Solar charge controllers

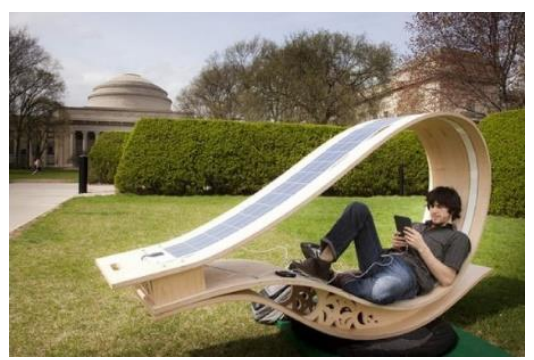

Figure 21. Solar charger

An innovative product UTL (Unite to light) multiplexing many applications. UTL is a solar powered portable lighting device much simpler in construction being superior to solar lanterns and lighting tubes. These devices are operable with rechargeable batteries and glowing LED's (Light emitting diodes). When MPPT is used and battery is charged in daytime, UTL gives good maintenance at night. Other additional features are detachable panel and electronic power management system. UTL is shown in Figure 22. 


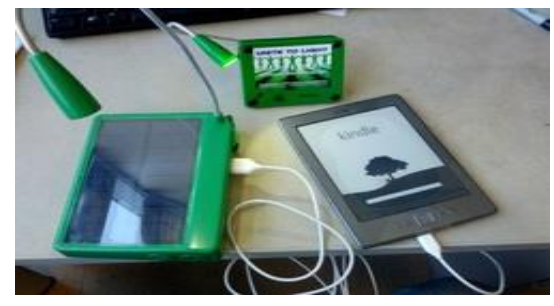

Figure 22. UTL for personal lighting arrangement

By endeavors of $R$ \& $D$ many solar appliances are innovated for solution to energy demand-supply crisis. Various solar plug in appliance as mini coolers and refrigerators in Figure 23, can be made to operate with full efficiency using MPPT.

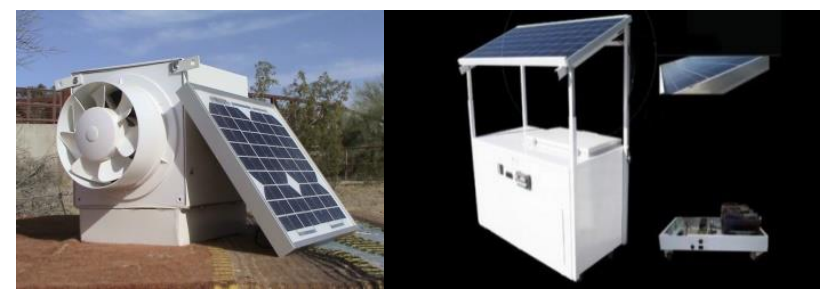

Figure 23. Solar powered cooler/refrigerator

Solar AC's and Solar Refrigeration is an adapting solution for climatic changes caused due to CFCs (Chlorofluorocarbons). Catering and household applications of solar may be done by box type solo or community cooker that may be constructed using single or double reflector units. In order to incorporate multitasking, baking units and solar canteens can be focused upon. Cooking vessels using parabolic arrays provide a source of large absorption of sun rays. Different types of solar cookers are shown in Figure 24.
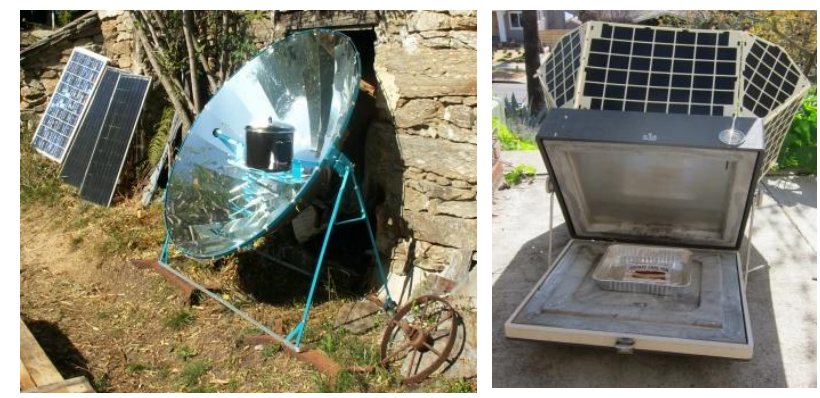

Figure 24. Parabolic solar cookers

e. Solar Waster Systems (SWS)

The unpredictability of direct water supply in hilly areas creates uncertainty always as concerns operated motors for and generator sets for water supply. Solar water pumps can be connected for water drinking or other purposes like space heating, cooling and drying, water desalination etc. Solar water heater uses convection process for movement of hot water in glazing and storage tanks made from blackboard paints or Gl sheets. Figure 25 shows Solar water pumps and sprayers for a single user in domestic purposes can be used to lift up water from underground. They can bore upto 100 meters and draw water out of grounds as in fountains or water boring systems in field when used in Uttarakhand region. 

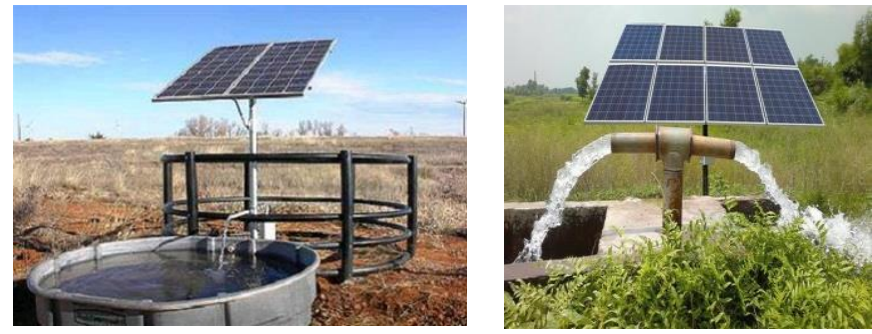

Figure 25. Solar water tank using motor

f. Other utility services (OUS)

Consumer product industries are focusing on solar integrated devices. Portable solar bags with adjustable mini panels act as power units in charging mobile phones. Solar calculators, watches, radios, headphones and alarms are being designed to meet standards of solar uses in industry. Solar clothes with solar caps mounted with lights can serve as torches at night. Umbrellas to capture energy in summers could be an effective application of solar followed by litted jewelry for women in decorative industry. These novel devices can be operated with MPPT integrated using a small chip. Some of these are shown in Figure 26.

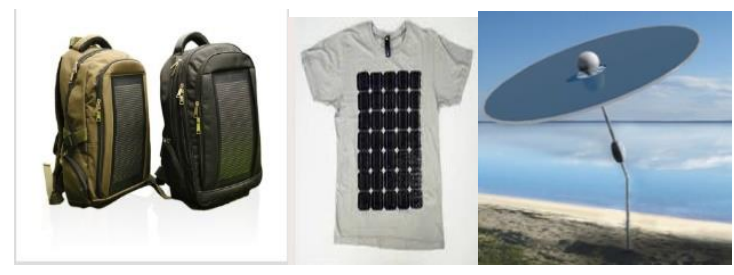

Figure 26. Body worn solar items

It is clear that the benefits of using MPPT module includes (a) working even when power out (b) no global warming as reduction of fossil fuels and generator sets (c) every time shining campus (d) no risk of shocking as safe for all and (e) SMART green-clean energy operation as they can be used for covering garbage dumps and road pits leading to better sewage system.

For MPPT system in present work, all accessories are assembled within same module and serve less complex structure related to orientation of system. Fuzzy intelligent controller used in MPPT also delivers robust response comparable with SCADA (Supervisory Control and Data Acquisition systems) presently used in PV supported tools. The system serves as an alternative to SCADA systems.

\section{Conclusion and Future Work}

With increase in solar PV applications, large number of small scale projects are avalible to develop entrepreneurs contributing to "Make in India" thereby increasing economic stability. Since energy is directly proportional to standard of living, the use of solar systems will revolutionize PV potential to a great extent in Uttarakhand.

The developed MPPT system has been simulated for variable temperature and irradiance conditions and delivers satisfactory response to maintain MPP. The MPPT system can be used in utility application based systems operating on $21 \mathrm{~V}$ or requiring $60 \mathrm{~W}$ for stand alone devices. By increasing number of panels wattage and load handling capability of stand alone system can be increased. 


\section{Acknowledgements}

Acknowledgements may be made to all those individuals and institutions not mentioned elsewhere in the paper but that made an important contribution.

\section{References}

[1] Energy Statistics 2014, Central Statistics Office, National Statistical Organization, Ministry of Statistics and Programme Implementation, Government of India, March 2015.

[2] Ministry of New \& Renewable Energy Report. Access to Clean Energy-A glimpse of off-grid projects in India. Government of India, New Delhi, 2012.

[3] Agro-climatic Zones in India, Indian Agricultural Statistics Research Institute, http://www.iasri.res.in/agridata.

[4] Uttarakhand Solar Power Policy: Ministry of New and Renewable Energy, New Delhi, 2013.

[5] http://www.ureda.uk.gov.in/.

[6] Ministry of New \& Renewable Energy Report. Jawaharlal Nehru National Solar Mission Phase II. Government of India, 2014.

[7] BC Ramachandraa, Rishabh Jain, Gautham, Krishnadas. Hotspots of solar potential in India. Renewable and Sustainable Energy Reviews. 2011; 15: 3178-3186.

[8] Bidyadhar Subudhi, Raseswari Pradhana. Comparative study on Maximum Power Point Tracking Techniques for Photovoltaic Power Systems. IEEE Transactions on Sustainable Energy. Jan 2013; 4(1): 89-98.

[9] http://www.solarelectricsupply.com/media/custom/upload/Solarex-MSX64.pdf.

[10] Chandani Sharma, Anamika Jain. Solar Panel Mathematical Modelling using Simulink. International Journal of Engineering Research and Applications. May 2014; 4(5) version 4: 67-72.

[11] Chandani Sharma, Anamika Jain. Simulink based Multivariable Solar Panel Modelling. Indonesian Journal of Electrical Engineering and Computer Science (IJEECS). August 2014; 12(8): 5784-5792.

[12] Chandani Sharma, Anamika Jain. Distributed MPP Tracking of PV through Buck Converter Using Fuzzy. Indonesian Journal of Electrical Engineering and Computer Science (IJEECS). August 2015; 15(2); 197-208.

[13] Chandani Sharma, Anamika Jain. Performance Comparison of PID and Fuzzy Controllers in Distributed MPPT. International Journal of Power Electronics and Drive Systems (IJPEDS). Sept 2015; 6(3): 625-635.

[14] Chandani Sharma, Anamika Jain. Modeling of Buck Converter Models in MPPT using PID and FLC. TELKOMNIKA. Dec 2015; 13(4): 1270-1280.

[15] Y Tian, CY Zhao. A Review of Solar Collectors and Thermal Energy Storage in Solar Thermal Applications.

[16] A Chaurey, TC Kandpal. Assessment and Evaluation of SPV Based Decentralized Rural Electrification: an Overview. Renewable and Sustainable Energy Reviews. 2010; 14: 2266-2278.

[17] TV Ramachandra. Solar energy potential assessment using GIS. Energy Educational Science Technology. 2007; 18; 101-114.

[18] "The Solar PV Landscape in India: An Industry Perspective" PV Group White Paper 2011.

[19] "India Solar PV Advisor" Guide by Energy Alternatives India (EAI).

[20] http://www.prosunindia.com/products/solar_power/solar_lantern_light.

[21] http://www.reuk.co.uk/Basic-4-AA-Solar-Battery-Charger-Plans.httml.

[22] http://www.unite-to-light.org.

[23] http://www.livingonsolar.com/solar-cooling.html.

[24] http://www.dpesolar.com/17612176801476-76.html.

[25] http://www.mondeosolar.com/solar-pumps-for-irrigation-fountains-wells.html.

[26] http://www.seia.org/policy/solartechnology/concentrating-solar-power.

[27] http://www.infinitesolarsolutions.com.

[28] http://www.gizmag.com/solar-powered-fridge-emily-cummins.

Bulletin of EEI Vol. 6, No. 2, June 2017 : 105-121 